\title{
Outpatient parenteral antimicrobial therapy
}

\author{
Kevin B Laupland MD MSc FRCPC ${ }^{1,2}$, Louis Valiquette MD MSc FRCPC 3
}

W e have witnessed major shifts in the delivery of health care from the hospital to community settings during the past decades, in part, due to technological improvements, medical cultural changes, cost-containment efforts and patient preferences. Central to this changing environment has been the development of outpatient parenteral antimicrobial therapy (OPAT) clinics and services. A wide range of OPAT treatment models have been adopted in many jurisdictions worldwide, and these have been shown to be safe and highly cost saving compared with inpatient management (1-10). In many regions, OPAT has become a significant part of the job description of adult infectious diseases specialists. Extensive reviews of OPAT program development and requirements have been published (11-13). In the present note, we briefly review the development, potential benefits and challenges associated with OPAT, and focus on contemporary issues relevant to adult infectious diseases specialists.

\section{HISTORY}

OPAT traces its origins to the 1970s $(12,14,15)$. In 1978, Stiver et al (15) published one of the first reports on the use of OPAT. The study involved 23 patients who were admitted to hospital with chronic infections in Winnipeg (Manitoba) and were subsequently discharged and successfully completed intravenous antimicrobial therapy as outpatients. During the 1980s and 1990s, an increasing number of reports were published, which principally described OPAT program development and documentated its safety and cost effectiveness. Early OPAT programs were focused on facilitating the discharge of stable inpatients with infections who, other than the requirement for prolonged intravenous antibiotic therapy, had no other need for inpatient care. During the past two decades, there have been an increasing number of descriptions of OPAT programs that have attempted to avoid hospitalization altogether for many patients with acute infections $(9,10,12,16,17)$.

\section{DELIVERY MODELS}

There has been a wide range of program descriptions published worldwide for the provision of OPAT $(6,12)$. Two key considerations in program delivery include the method(s) by which the antimicrobial is administrated and how patients are monitored during therapy. The main administration models presently being used may be classified as infusion clinics/centres, provider-based inhome health care and selfadministration.

Patients travel to ambulatory infusion centres on a regular basis to receive their treatments $(4,18)$. These infusion centres may be housed within the day-care areas of hospitals or be freestanding clinics or physician offices in the community. In some cases, the emergency department may be used for this purpose. The infusion centre model has major advantages for the efficient delivery of care, including keeping staff and services within one location and having the ability to treat numerous patients simultaneously. In addition, monitoring is facilitated because patients are regularly assessed. However, if typical business hours are observed, one potential drawback is the inablilty to provide dosing of drugs more than once per day. Furthermore, the requirement for patient travel to the clinic may be inconvenient, expensive and exclude patients with limited mobility.
Inhome provider models require trained health care providers to attend to patients in their personal domiciles for infusions. Typically, patients are first assessed in a hospital or at an ambulatory care clinic before prescription, although this may be achieved entirely using home visits initiated by physician house calls (19). The primary advantages of inhome delivery models are that patients are regularly monitored and that patient travel is minimized. However, the principal drawbacks are related to inefficiencies in delivery that arise from the requirement for health care workers to regularly travel to patients' homes. This is particularly relevant in geographically dispersed areas or in cases for which multiple daily dosages are required. In addition, issues of health care provider safety may present a concern.

Patients may self-administer infusions using gravity, syringes, elastomeric infusion systems or mechanical infusion pumps. With the first three methods, patients will need to connect the supply of drug and its associated tubing to their pre-existing intravenous access for each individual infusion and disconnect them after each dose. With mechanical infusion pumps, a programmed pump may be used to administer doses (5). This is particularly useful when multiple daily doses are prescribed because the drug can be infused at programmed intervals and patients only have to change the supply of drug once per day $(18,20)$. Both elastomeric infusion systems and infusion pumps may be used for continuous slow infusions. The key advantage of the self-administration models are patient convenience because they can set their own schedule and are not required to stay in their own home to perform the infusion. The disadvantages are potentially numerous and include the fact that patients must possess the dexterity and training to perform the necessary tasks, direct monitoring with each dose does not occur and that mechanisms must be in place to manage intravenous access problems (ie, loss of access) because these can not be self-corrected. In addition, because having patients solubilize drugs for injection is potentially unsafe, patients will need to either personally collect premixed bags of antibiotics for infusions or have them delivered (5). As a result, antibiotics that are unstable in solution may not be practical for use with self-administration.

\section{SAFETY}

There are a number of potential safety concerns associated with the treatment of infections using parenteral therapy for patients in the ambulatory setting. Most of these potential safety concerns relate to the specific complications associated with the infections per se, the route of intravenous access and reactions/intolerances to the administered drugs (18). Use of a multidisciplinary team-based approach has been emphasized in numerous publications to reduce the occurence of potential adverse events and to improve outcomes $(13,21)$.

A wide variety of infections have been reported as being safely treated using OPAT $(2,5,7,10,11,18)$. It is evident that patients with severe acute infections, those who require close monitoring or adjunctive therapies (ie, oxygen, frequent blood testing, bolus intravenous fluid therapy, surgical intervention) are not good candidates for OPAT and are best managed in an inpatient setting. On the other hand, it is intuitive that chronic infections, such as extremity osteomyelitis or those acute infections that have been demonstrated to exhibit good clinical response after days or weeks of inpatient therapy, can be safely treated in the outpatient setting. These generally include

\footnotetext{
${ }^{1}$ Departments of Medicine, Critical Care Medicine, Pathology and Laboratory Medicine and Community Health Sciences, University of Calgary, Calgary, Alberta; ${ }^{2}$ Department of Medicine, Royal Inland Hospital, Kamloops, British Columbia; ${ }^{3}$ Department of Microbiology-Infectious

Diseases, Université de Sherbrooke, Sherbrooke, Quebec

Correspondence: Dr Kevin B Laupland, Royal Inland Hospital, Kamloops, British Columbia V2C 2T1. Telephone 250-299-5675,

fax 778-471-1789, e-mail klaupland@gmail.com
} 
bone and joint infections $(5,22)$, selected cases of endocarditis $(18,23$ 25 ) and deep visceral abscesses (26). Many OPAT programs have limited patient enrollment for these chronic infections $(15,23,26)$. However, experience using OPAT management with selected acute infections, often without initial inhospital treatment, is growing and includes infections of the skin and soft tissue; the urinary, respiratory and gastrointestinal tracts; as well as other acute infections $(1,3,9,10,17,19,27-29)$. While most OPAT treatments involve the use of antibacterials, OPAT may also include the use of antiviral, antifungal or antiparasitic agents.

Although some programs have relied heavily on the use of intramuscular injections, the vast majority of OPAT programs are based on the provision of intravenous injections (6). As a result, safe and reliable intravenous access is a mandatory component of OPAT. Generally, peripheral intravenous access is the simplest to obtain and provides a good option for treatments of short duration (days to weeks), whereas midline catheters and peripherally inserted central catheters are better suited for treatment durations lasting weeks to months (30). When prolonged therapy is required and the use of peripherally inserted central catheters is not feasible, some patients may require tunnelled central venous catheters. Two important issues have been raised regarding this form of access for use with OPAT. Concerns exist with the use of self-administration regarding the risk for the development of infection. However, with proper training and programmatic support, this does not appear to be a limiting factor $(30,31)$. Most programs consider injection drug use a contraindication to OPAT. However, some programs have reported success using OPAT with selected patients in this population (32).

\section{THE INFECTIOUS DISEASES SPECIALIST AND OPAT}

Although the provision of OPAT in many jurisdictions is performed by infectious diseases specialists, in other jurisdictions, there are few limitations on who may act as a provider, with generalist and specialist physicians as well as nonphysicians, in some cases, being able to prescribe OPAT therapies (33). Given their specialized expertise, it appears reasonable to assume that OPAT that is prescribed by infectious diseases specialists is more likely to be narrower in spectrum, of potentially higher efficacy and of shorter duration compared with nonspecialist care. Several studies have reported that a team-based approach that includes an infectious disease specialist leads to optimized therapy (3436). However, infectious diseases specialists potentially must fufill many diverse roles with respect to inpatient consultation, infection prevention and control programs, antimicrobial use and chronic infectious diseases management, such as in HIV and hepatitis clinics. As a result, human resource limitations may play a role in the ability to staff OPAT clinics solely with infectious diseases specialists.

\section{PRESENT AND FUTURE CHALLENGES}

While OPAT has provided many patients with improved satisfaction in care, saved health care resources, and helped to offload emergency departments and inpatient beds, a number of challenges and controversies remain.

Compared with inpatient care, OPAT is clearly cost saving; however, issues remain with respect to its funding because it may shift costs from hospitals to patients (7). For example, when patients are admitted to hospital in Canada, all necessary care is provided to Canadian citizens through the publicly-funded health care system. However, when discharged through OPAT, the costs of drugs and other supplies are not guaranteed to be paid through the public health care system. Of the 71 assessed inpatients who were receiving intravenous therapy in a study conducted in Vancouver (British Columbia) (37), 64 indicated a preference for further treatment at home versus inhospital treatment, and this was associated with a median willingness to pay of $\$ 490$. It is our view that OPAT should be considered and extension or replacement of inpatient care and should be funded accordingly.

Another potential consideration with the availability of OPAT is that by increasing ready access to intravenous therapy, physician referral behaviour and patient expectations may change. On one hand, efficient access to OPAT may lead to an increasing expectation for intravenous treatment of patients who may have relatively mild disease and who may be successfully treated using oral agents. On the other hand, due to increasing stress on hospital capacity in many jurisdictions, there may be expectations to treat sicker patients as outpatients who may be better treated and monitored in the hospital setting.

A central principle of antimicrobial prescription is to use the narrowest spectrum agent that has acceptable efficacy. However, many OPAT systems, especially those that use the infusion centre or inhome health care worker models, use broad spectrum drugs that have prolonged half-lives, such as ceftriaxone or ertapenem, in preference to narrower-spectrum choices that require more frequent dosing (38). This may be a practical consideration in many programs in which the only alternative may be admission to hospital. While it is quite possible that there may be an overall benefit to outpatient care and the use of once-daily broad spectrum agents compared with narrowerspectrum treatment in hospital due to less exposure to resistant organism acquisition, this remains contrary to infectious diseases teachings and practice. The availability of elastomeric and mechanical infusion pumps do provide an option for frequent dosing of agents with short half-lives and provide a suitable alternative to inhospital treatment.

Perhaps the most significant concern with OPAT is that while it has been embraced and adopted widely, evaluation of OPAT has been largely experiential and observational in nature. Assessment of OPAT in clinical trials has been noticeably lacking (39). There are many questions regarding optimal therapeutic agents, administration route and duration, as well as programmatic and delivery issues in OPAT that remain unanswered. The increasing burden of antimicrobial resistance will inevitably have an increasing influence on OPAT practice and demand in the coming years. Given the vast number of patients treated annually using OPAT programs worldwide, we must push for greater scrutiny of our practices and argue for enhanced research resources to optimize the use of OPAT.

\section{REFERENCES}

1. Nathwani D. The management of skin and soft tissue infections: Outpatient parenteral antibiotic therapy in the United Kingdom. Chemotherapy 2001;47(Suppl 1):17-23.

2. Chambers S, Gallagher K, Metcalf S, Pithie A. Home intravenous antimicrobial service - twelve months experience in Christchurch. N Z Med J 2002;115:216-8.

3. Barr DA, Semple L, Seaton RA. Outpatient parenteral antimicrobial therapy (OPAT) in a teaching hospital-based practice: A retrospective cohort study describing experience and evolution over 10 years. Int J Antimicrob Agents 2012;39:407-13.

4. Bazaz R, Chapman AL, Winstanley TG. Ertapenem administered as outpatient parenteral antibiotic therapy for urinary tract infections caused by extended-spectrum-beta-lactamase-producing Gramnegative organisms. J Antimicrob Chemother 2010;65:1510-3.

5. Bernard L, El H, Pron B, et al. Outpatient parenteral antimicrobial therapy (OPAT) for the treatment of osteomyelitis: Evaluation of efficacy, tolerance and cost. J Clin Pharm Ther 2001;26:445-51.

6. Esposito S, Noviello S, Leone S, et al. Outpatient parenteral antibiotic therapy (OPAT) in different countries: A comparison. Int J Antimicrob Agents 2004;24:473-8.

7. Fisher DA, Kurup A, Lye D, et al. Outpatient parenteral antibiotic therapy in Singapore. Int J Antimicrob Agents 2006;28:545-50.

8. Gray A, Dryden M, Charos A. Antibiotic management and early discharge from hospital: An economic analysis.

J Antimicrob Chemother 2012;67:2297-302.

9. Kieran J, O’Reilly A, Parker J, Clarke S, Bergin C. Self-administered outpatient parenteral antimicrobial therapy: A report of three years experience in the Irish healthcare setting. Eur J Clin Microbiol Infect Dis 2009;28:1369-74.

10. Wai AO, Frighetto L, Marra CA, Chan E, Jewesson PJ. Cost analysis of an adult outpatient parenteral antibiotic therapy (OPAT) programme. A Canadian teaching hospital and Ministry of Health perspective. Pharmacoeconomics 2000;18:451-7.

11. Tice AD, Rehm SJ, Dalovisio JR, et al. Practice guidelines for outpatient parenteral antimicrobial therapy. IDSA guidelines. Clin Infect Dis 2004;38:1651-72. 
12. Paladino JA, Poretz D. Outpatient parenteral antimicrobial therapy today. Clin Infect Dis 2010;51(Suppl 2):S198-208.

13. Chapman AL, Seaton RA, Cooper MA, et al. Good practice recommendations for outpatient parenteral antimicrobial therapy (OPAT) in adults in the UK: A consensus statement. J Antimicrob Chemother 2012;67:1053-62.

14. Rucker RW, Harrison GM. Outpatient intravenous medications in the management of cystic fibrosis. Pediatrics 1974;54:358-60.

15. Stiver HG, Telford GO, Mossey JM, et al. Intravenous antibiotic therapy at home. Ann Intern Med 1978;89:690-3.

16. Laupland KB, Gill MJ, Schenk L, Goodwin D, Davies HD. Outpatient parenteral antibiotic therapy: Evolution of the Calgary adult home parenteral therapy program. Clin Invest Med 2002;25:185-90.

17. Seaton RA, Sharp E, Bezlyak V, Weir CJ. Factors associated with outcome and duration of therapy in outpatient parenteral antibiotic therapy (OPAT) patients with skin and soft-tissue infections. Int J Antimicrob Agents 2011;38:243-8.

18. Amodeo MR, Clulow T, Lainchbury J, et al. Outpatient intravenous treatment for infective endocarditis: Safety, effectiveness and one-year outcomes. J Infect 2009;59:387-93.

19. Theocharis G, Rafailidis PI, Rodis D, Kontopidis I, Barbas SG, Falagas ME. Outpatient parenteral antibiotic therapy (OPAT) at home in Attica, Greece. Eur J Clin Microbiol Infect Dis 2012;31:2957-61.

20. Ingram PR, Lye DC, Fisher DA, Goh WP, Tam VH. Nephrotoxicity of continuous versus intermittent infusion of vancomycin in outpatient parenteral antimicrobial therapy. Int J Antimicrob Agents 2009;34:570-4.

21. Heintz BH, Halilovic J, Christensen CL. Impact of a multidisciplinary team review of potential outpatient parenteral antimicrobial therapy prior to discharge from an academic medical center. Ann Pharmacother 2011;45:1329-37.

22. Mackintosh CL, White HA, Seaton RA. Outpatient parenteral antibiotic therapy (OPAT) for bone and joint infections: Experience from a UK teaching hospital-based service. J Antimicrob Chemother 2011;66:408-15.

23. Partridge DG, O'Brien E, Chapman AL. Outpatient parenteral antibiotic therapy for infective endocarditis: A review of 4 years' experience at a UK centre. Postgrad Med J 2012;88:377-81.

24. Andrews MM, von Reyn CF. Patient selection criteria and management guidelines for outpatient parenteral antibiotic therapy for native valve infective endocarditis. Clin Infect Dis 2001;33:203-9.

25. Larioza J, Heung L, Girard A, Brown RB. Management of infective endocarditis in outpatients: Clinical experience with outpatient parenteral antibiotic therapy. South Med J 2009;102:575-9.

26. Chan DS, Archuleta S, Llorin RM, Lye DC, Fisher D. Standardized outpatient management of Klebsiella pneumoniae liver abscesses. Int J Infect Dis 2012;13:e185-8. [Epub ahead of print].
27. White B, Seaton RA, Evans TJ. Management of suspected Lyme borreliosis: Experience from an outpatient parenteral antibiotic therapy service. QJM 2013;106:133-8.

28. Ingram PR, Cerbe L, Hassell M, Wilson M, Dyer JR. Limited role for outpatient parenteral antibiotic therapy for community-acquired pneumonia. Respirology 2008;13:893-6.

29. Laupland KB, Davies HD. Olecranon septic bursitis managed in an ambulatory setting. The Calgary Home Parenteral Therapy Program Study Group. Clin Invest Med 2001;24:171-8.

30. Barr DA, Semple L, Seaton RA. Self-administration of outpatient parenteral antibiotic therapy and risk of catheter-related adverse events: A retrospective cohort study. Eur J Clin Microbiol Infect Dis 2012;31:2611-9.

31. Matthews PC, Conlon CP, Berendt AR, et al. Outpatient parenteral antimicrobial therapy (OPAT): Is it safe for selected patients to selfadminister at home? A retrospective analysis of a large cohort over 13 years. J Antimicrob Chemother 2007;60:356-62.

32. Ho J, Archuleta S, Sulaiman Z, Fisher D. Safe and successful treatment of intravenous drug users with a peripherally inserted central catheter in an outpatient parenteral antibiotic treatment service. J Antimicrob Chemother 2010;65:2641-4.

33. Chary A, Tice AD, Martinelli LP, Liedtke LA, Plantenga MS, Strausbaugh LJ. Experience of infectious diseases consultants with outpatient parenteral antimicrobial therapy: Results of an emerging infections network survey. Clin Infect Dis 2006;43:1290-5.

34. Dryden M, Saeed K, Townsend R, et al. Antibiotic stewardship and early discharge from hospital: Impact of a structured approach to antimicrobial management. J Antimicrob Chemother 2012;67:2289-96.

35. Gilchrist M, Franklin BD, Patel JP. An outpatient parenteral antibiotic therapy (OPAT) map to identify risks associated with an OPAT service. J Antimicrob Chemother 2008;62:177-83.

36. Sharma R, Loomis W, Brown RB. Impact of mandatory inpatient infectious disease consultation on outpatient parenteral antibiotic therapy. Am J Med Sci 2005;330:60-4.

37. Marra CA, Frighetto L, Goodfellow AF, et al. Willingness to pay to assess patient preferences for therapy in a Canadian setting. BMC Health Serv Res 2005;5:43.

38. Duncan CJ, Barr DA, Seaton RA. Outpatient parenteral antimicrobial therapy with ceftriaxone, a review. Int J Clin Pharm 2012;34:410-7.

39. Corwin P, Toop L, McGeoch G, et al. Randomised controlled trial of intravenous antibiotic treatment for cellulitis at home compared with hospital. BMJ 2005;330:129. 


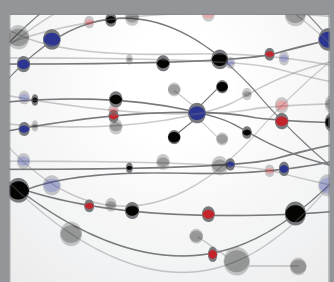

The Scientific World Journal
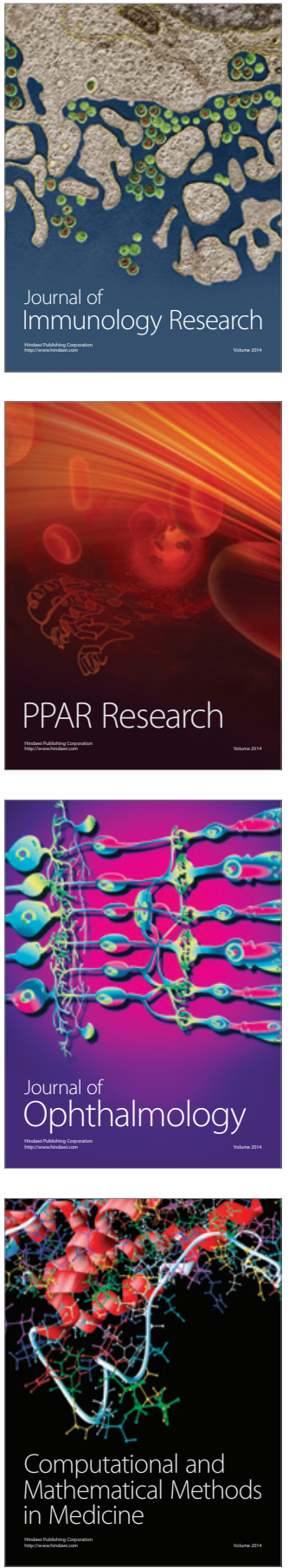

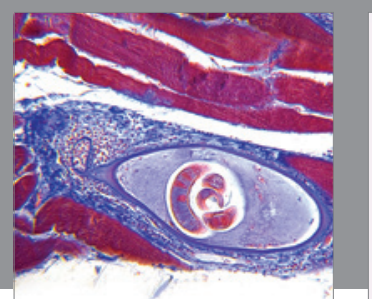

Gastroenterology Research and Practice

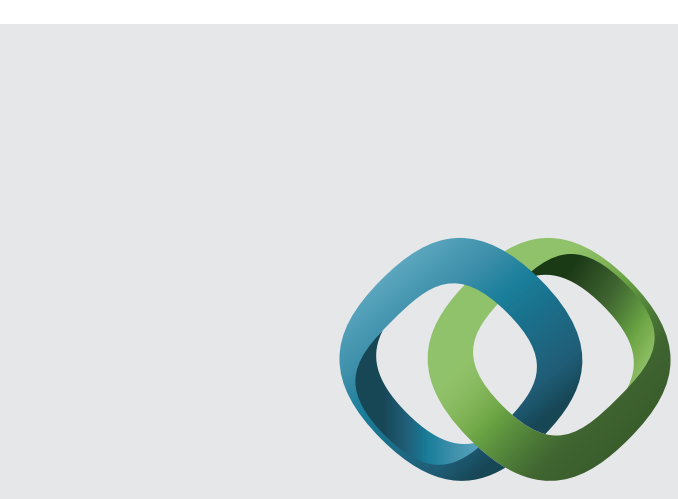

\section{Hindawi}

Submit your manuscripts at

http://www.hindawi.com
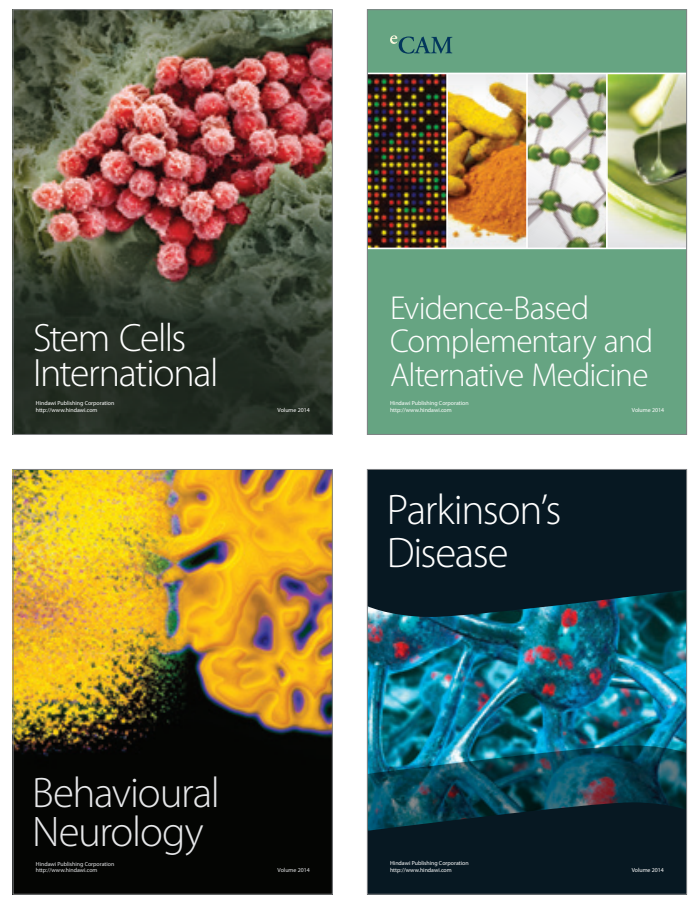
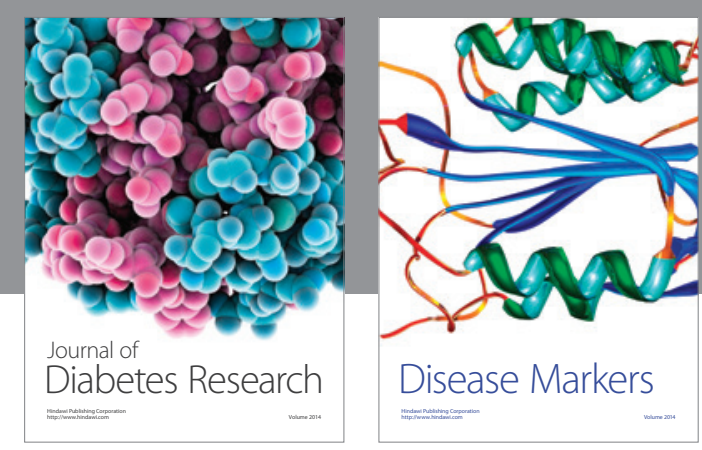

Disease Markers
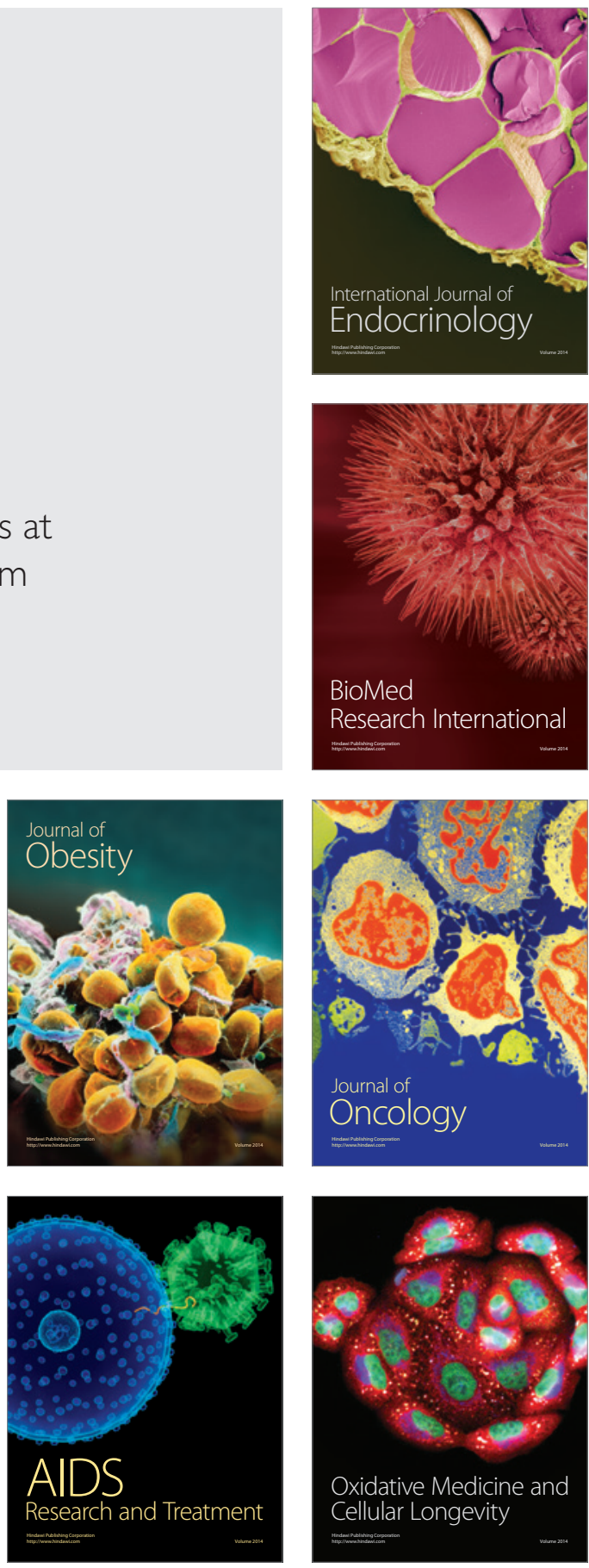